\title{
Research on the Application of Unity3D in the Protection and Inheritance of Intangible Cultural Heritage
}

\author{
Hongjun Zhang ${ }^{1} \&$ Kehui Deng ${ }^{1}$ \\ ${ }^{1}$ College of Humanities, Donghua University, Shanghai, China \\ Correspondence: Zhang Hongjun, Room 359, College Building No. 1, School of Humanities, Donghua \\ University, Shanghai, China. Tel: 86-138-1786-5812. E-mail: zhjun77@dhu.edu.cn
}

Received: September 25, 2019

Accepted: October 14, $2019 \quad$ Online Published: October 24, 2019

doi:10.5539/ass.v15n11p89

URL: https://doi.org/10.5539/ass.v15n11p89

Foundation item: This research was supported by "the Fundamental Research Funds for the Central Universities".

\begin{abstract}
Intangible Cultural Heritage is an important part in the soul of a region. The protection and inheritance of existing intangible cultural heritage projects are of great historical and realistic significance to the historical and cultural heritage of the city and the promotion of national, scientific and popular socialist culture. Unity3D is a comprehensive game engine based on multi-platform, it has the characteristics of specialization, and it also has obvious effect in other fields. This article focuses on the application of unity $3 \mathrm{~d}$ in the field of protection and inheritance of intangible cultural heritage, summarizes the general process and matters needing attention in the production of protection and inheritance works and hopes to provide some help for future related work.
\end{abstract}

Keywords: virtual reality(vr), intangible cultural heritage(ich), unity3d

The protection of intangible cultural heritage started late in China. The National Digital Library Project was launched and the digitization process of cultural resources began in 1996. In August 2004, China formally became a party to the Convention on the Protection of the Intangible Cultural Heritage of UNESCO, and became one of the earliest countries to accede to the Convention. On March 31, 2005, the General Office of the State Council issued the Opinions of the General Office of the State Council on Strengthening the Protection of China's Intangible Cultural Heritage. It clearly stated that "the intangible cultural heritage should be authentic, systematic and complete and establishment of archives and databases by means of writing, recording, video and digital multimedia". On February 25, 2011, the Law of the People's Republic of China on Intangible Cultural Heritage was formally adopted and implemented by the 19th meeting of the Standing Committee of the Eleventh National People's Congress of the People's Republic of China, and further standardized the protection work from the legal level. During the Eleventh Five-Year Plan period, the State incorporated the digitization of cultural heritage into the National 863 Plan and the National Science and Technology Support Plan. Among them, "Research on Key Technologies of Cultural Heritage Protection", "Research and Development of Key Technologies of Large Site Protection", "Research and Demonstration of Key Technologies of Network Culture Security and National Culture Digitization" and other items are included in the national science and technology support plan, focusing on solving key technologies, common technologies and public issues in the field of cultural heritage protection in China. Beneficial and technical issues. The newly issued "13th Five-Year Plan" clearly points out that we should vigorously develop creative cultural industries, promote the integration of culture and technology, information, tourism, sports, finance and other industries, and formulate and implement the revitalization plan of China's traditional crafts, support traditional crafts projects, and create a number of well-known brands with national characteristics. In January 2017, the General Office of the Central Committee of the Communist Party of China and the General Office of the State Council issued Opinions on the Implementation of the Project for the Inheritance and Development of Chinese Excellent Traditional Culture, which once again emphasized the importance of inheriting and developing Chinese Excellent Culture. The intangible cultural heritage is an important part of the soul of the region. Protecting and inheriting the existing intangible cultural heritage projects is of great historical and practical significance to the historical and cultural heritage of the city and to the promotion of national, scientific and popular socialist culture. 


\section{Current Situation and Problems of Protection and Inheritance of Intangible Cultural Heritage}

The Interim Measures for the Declaration and Assessment of National Non-material Cultural Heritage Representatives promulgated by the State Council defines intangible cultural heritage as follows: "The intangible cultural heritage refers to various forms of traditional culture which are inherited from generation to generation by people of all nationalities and closely related to the life of the masses (Such as folk activities, performing arts, traditional knowledge and skills as well as related utensils, objects and handicrafts) and cultural space". Its scope includes: firstly, oral tradition, including language as a carrier of culture; secondly, traditional performing arts; thirdly, custom activities, etiquette, festivals; fourthly, folk traditional knowledge and practice concerning nature and the universe; fifth, traditional handicraft skills; sixth, cultural space related to the above-mentioned manifestations". As a very special cultural carrier, traditional means of protection are various. The most common forms are the following five ways: establishing folk villages, protecting inheritors and heirs, preserving precious materials in libraries and museums, using education (especially school education) to inherit and propagandizing tourism development. However, due to its "invisible" state characteristics and the rapid development of society, various drawbacks appear to some extent for people's propaganda and protection of these traditions.

First, non-physical characteristic. Intangible cultural heritage is basically expressed through the mouth, hands, limbs, behavior and skills, and its completion process and heritage system are entirely dependent on people, which determines its "intangible" and "live" nature that the art would disappear with the death of people.

Second, inheritance uncertainty. Intangible cultural heritage exists on the basis of people, a special carrier, applies voice, image and handicraft skills as the means of expression, and uses inheritance modes of conducting oral teaching to inspire true understanding and teaching by precept and example. The inheritance relies on the subjectivity of inheritor too much, so the personal factors of the inheritor bring great uncertainty to the protection of intangible cultural heritage.

Third, lagging and single protection method. The method to protect the traditional technologies of intangible cultural heritage is single, mainly through pictures, text, recording, video, etc. to save, while there is no specific complete protection program. When political events, war, natural disasters, etc. occur, these information is difficult to save, and also difficult to recover once being lost.

Last not the least, it is difficult to conduct protection and innovative development due to remote geographical location. Intangible cultural heritage can not be separated from specific national culture and regional culture, and is the embodiment of local culture and life style. At present, most of the precious intangible cultural heritage sites are located in remote city corner or rural areas, and some even in the undeveloped remote mountains, which makes intangible cultural heritage difficult to protect and more difficult to carry out innovative development.

\section{Main Characteristics and Advantages of Unity3D Technology}

Unity3D was originally a development tool and game engine suite, including graphics, audio, physics, network and other engine support, and has a very powerful editor to integrate all this. Use Mono as the virtual machine of the script engine, and use C\# or a language similar to Java Script as the script language. It supports a variety of formats of audio and video resources, with lighting effect and rich UI interface. The engine supports Shader Language Programming and can be released on multiple platforms. Its own Asset Store library provides a wealth of resource sharing plug-ins, and its unique Pyhsic physical system. Unity3D is a virtual reality development platform with high efficiency, vivid effect, strong interaction ability and small amount of data. Therefore, Unity3D is widely used in aerospace, education and military fields nowadays. Obviously, there should be no problem in its application and popularization in the protection and dissemination of intangible cultural heritage. The application of virtual reality based on Unity3D in the field of intangible cultural heritage protection and dissemination has the following advantages:

First of all, perfect light and shadow effects can vividly express teaching concepts and reflect constructivism. It can vividly reproduce geographical knowledge, historical events, natural phenomena and other content, set up scenarios for learners, take students as the center, and acquire knowledge through experience.

In addition, compared with VRML/X3D in the past, Unity adopts the idea of component design, which reduces the complex programming work and facilitates the efficient development. Through Java Script, C\#, Boo script design, any intelligent interactive work can be achieved, and learners can manipulate objects and interact with teaching content as in the real world. In addition, Unity file data volume is small, which can realize web page transmission, creating conditions for the emergence of three-dimensional distance education websites. In the three-dimensional teaching website, learners can produce from one scene to another, more in line with the real way of thinking. 
Finally, support multi-person online collaboration to realize virtual learning community. Learners can register in the virtual community, through role-playing, collaborative learning; support real-time 3D graphics mixed audio and video streams, conducive to the dissemination of teaching resources, learners can quickly access multimedia teaching materials; support iPhone publishing, so as to facilitate mobile learning. Students can $\log$ on to the virtual teaching system anytime and anywhere to search for information and ask questions. Through Unity to connect to the database, teaching information query can be realized, and efficient information-based teaching can be realized.

In short, the advantages of unity $3 \mathrm{~d}$ can effectively solve the difficulties and problems encountered in the protection of intangible cultural heritage.

\section{General Procedures and Notices for Making Works of Intangible Cultural Heritage by Unity3d}

\subsection{General Procedures}

It is a systematic project to protect and dissemination of intangible cultural heritage by using information technology based on unity3d. Its general process is as follows:

1) Write scripts to determine project plans according to project objectives.

2) Collect and sort out the relevant information and data of intangible cultural heritage.

3) Design and Making of 3D Model of intangible cultural heritage.

4) Create Unity3d project, import 3D model and other resources.

5) Create scenarios and place objects.

6) Layout of lights and cameras.

7) Setting up components and writing scripts.

8) Debug, test and release.

9) Operation, maintenance and optimization.

\subsection{Notices}

The author summarizes the following points for reference, In order to ensure the normal research and development of works and improve efficiency.

\subsubsection{Units and Proportions Need to Be Unified}

The unit and scale settings of the model used in the same scene must be the same, so as to ensure the normal display of the model in unity $3 \mathrm{~d}$. Otherwise, some anomalies will appear, such as inconsistent size and inconsistent columns.

\subsubsection{D Model Needs Specification}

All role models are best situated at the origin. Without specific requirements, the center of the object must be the axis. Each grid model of mobile devices is controlled in 300-1500 triangles, which will achieve better results. For desktop platforms, the theoretical range is $1500-4000$. If there are a large number of characters on the screen at any time in the game, then the number of characters should be reduced. Check the model file carefully, try to maximize the optimization, delete unnecessary faces where you can't see, merge disconnected vertices and remove isolated vertices.

\subsubsection{Material and Texture Also Need Specification}

(a) Unity3d software only supports standard and Multi/Sub-Object materials. (b) Unity3d currently only supports Bitmap mapping types, but not all other mapping types. Only Diffuse Color (diffuse reflection) and self-Illumination (self-luminescence, used to export light map) mapping channels are supported. (c) It requires the original mapping to be JPG without channel, 32-bit TGA or PNG with channel, and the maximum size should not exceed 2048. The maximum mapping size of the $\mathrm{N}$-th power $(8,16,32,64,128,256,512,1024)$ of the mapping file should not exceed 1024 x 1024 . Under special circumstances, the size can be adjusted within these ranges. (d) Maps can not be named in Chinese, can not be renamed. (e) The naming of material ball is the same as that of object, and the naming of parent-child hierarchy of material ball must be the same. (f) The same texture must use a material ball. (g) Except for objects that need to be represented by double-sided materials, other objects should not be made of double-sided materials. (h) Material ID must be the same as object ID number. (i) When baking with complete map, a shell material will be generated automatically after baking. The shell material must be changed into standard material, and the channel must be consistent, otherwise the 
mapping can not be correctly derived. (j) Maps with Alpha channels are stored in TGA or PNG format and must be named with al to distinguish them. $(\mathrm{k})$ The model needs to make texture with channel when it is processed through channel. For example, in the process of making the channel texture of trees, because the channel texture takes up more common texture of the same size of resource coins in the process of program rendering, it is better to change the transparent part to the main color of trees, so that the color of the effective edge part can be corrected in rendering.

\subsubsection{Notices for Model Output}

(a) Change baking material to standard material ball, channel 1, self-luminescence 100\%; (b) 2. So the object name, material ball name and texture name are consistent; (c) Merge vertices, clear scenes, delete all useless objects; (d) Clean the material balls and delete the redundant material balls (minor maps should be reduced); (e) Export .FBX files as required (check whether to export in groups). After exporting fbx, re-import it into Max to see if the animation of FBX is correct; (f) Check whether the documents are correct according to the acceptance form.

\subsubsection{Document Backup and Submission Must Comply with Standards}

The final confirmed Max files are stored in the corresponding "project name/model/char", "project name/model/scene", "project name/model/prop" folders of the server, including role model, scene model and prop model. The animation file is stored in the anim folder. Second, export to program obj, .FBX files and other format files uniformly stored in export folder subfolders anim, model, prop.

\section{Conclusion}

Unity3D technology, one of the virtual reality technologies, which integrates computer graphics, multimedia, sensors, human-computer interaction, network, stereo display and simulation, can record and present the cultural memory and reproduction of intangible cultural heritage in order to continue the traditional context of intangible cultural heritage. Now it is one of the main ways of sustainable development in modern society. It is hoped that the discussion in this paper can provide people with a more complete understanding and help the development of the protection and inheritance of intangible cultural heritage by applying Unity3D technology.

\section{References}

China Intangible Cultural Heritage Network. (2016). Digital Museum of China Intangible Cultural Heritage. Retrieved from http://www.ihchina.cn/

General Office of the State Council. (2006). Opinions of the General Office of the State Council on Strengthening the Protection of Intangible Cultural Heritage in China. Retrieved from http://www.gov.cn/zwgk/2005-08/.15/content_21681.htm

General Office of the State Council. (2006). The Eleventh Five-Year Plan Outline of National Economy and Social Development of PRC. Retrieved from http://www.gov.cn/ztzl/gmjj/index.htm

General Office of the State Council. (2016). The Thirteenth Five-Year Plan Outline of National Economy and Social Development of PRC. Retrieved from http://news.cntv.cn/special/sswgh/

Kato, K. (2007). Prayers for the Whales: Spirituality and Ethics of a Former Whaling Community- Intangible Cultural Heritage for Sustainability. International Journal of Cultural Property, 14(3), $283-313$. https://doi.org/ 10.1017/S0940739107070191

Kurin, R. (2010). Safeguarding Intangible Cultural Heritage in the 2003 UNESCO Convention: A critical appraisal. Museum International, 56(1-2), 66-77. https://doi.org/10.1111/j.1350-0775.2004.00459.x

UNESCO. (2003). Convention for the Safeguarding of the Intangible Cultural Heritage 2003. Retrieved from http://portal.unesco.org/en/ev.php-URL_ID=17716\&URL_DO=DO_TOPIC\&URL_SECTION=201.html

\section{Copyrights}

Copyright for this article is retained by the author(s), with first publication rights granted to the journal.

This is an open-access article distributed under the terms and conditions of the Creative Commons Attribution license (http://creativecommons.org/licenses/by/4.0/). 